\title{
Dinâmica na produção e na diversificação das culturas cultivadas no Espírito Santo de 1970 a 2010
}

\author{
Niraldo José Ponciano* \\ Joesi de Souza Castro*** \\ Paulo Marcelo de Souza**** \\ Magda Aparecida Nogueira***** \\ Marlon Gomes Ney ${ }^{* * * * * *}$
}

\begin{abstract}
Resumo
O trabalho objetivou analisar a dinâmica das principais culturas no Estado do Espírito Santo, no período de 1970 a 2010. Empregou-se o método shift-share para quantificar variação de área, rendimento, localização geográfica e índices de diversificação de área e de valor da produção. Constatou-se que houve alterações de área, de produção e de produtividade. Nas quatro décadas analisadas, a cultura do café apresentou maior expansão em área (148\%), com efeitos positivos tanto em escala, quanto em substituição. Enquanto as culturas de milho, de arroz e de feijão foram as que mais decresceram em área, com efeitos negativos tanto em escala, quanto em substituição. Suas taxas de produção foram negativas, com redução de efeitos área e de rendimento. O índice de diversificação revelou que houve concentração de área em poucos produtos.
\end{abstract}

Palavras-chave: Agricultura capixaba. Diversificação. Efeito área e de rendimento. Método shift-share.

Doutor em Economia Rural pela UFV. Professor da Universidade Estadual do Norte Fluminense Darcy Ribeiro. E-mail: njponciano@gmail.com

** Doutor em Produção Vegetal pela UENF. Professor do Instituto Federal de Ciência e Tecnologia do Espírito Santo. E-mail: jcastro@ifes.edu.gov.br

**** Doutor em Economia Aplicada pela UFV. Professor da Universidade Estadual do Norte Fluminense Darcy Ribeiro. E-mail: pmsouza@gmail.com

**** Doutora em Economia Aplicada pela UFV. Professora da Universidade Federal do Espírito Santo. E-mail: magdanogueira@hotmail.com

****** Doutor em Economia Aplicada pela Unicamp. Professor da Universidade Estadual do Norte Fluminense Darcy Ribeiro. E-mail: marlonney@uenf.br

http://dx.doi.org/10.5335/rtee.v23i48.7361

Submissão: 19/04/2016. Aceite: 20/04/2017. 


\section{Introdução}

Nas últimas décadas, as principais culturas cultivadas no estado do Espírito Santo apresentaram alterações na formação da produção, no nível tecnológico e nos fatores de produção. Acredita-se que a maioria das mudanças tenha decorrido, principalmente, da criação e da implementação de políticas agrícolas, originadas de diferentes esferas governamentais e dos preços dos mercados nacionais e internacionais.

A partir da década de 70, verificaram-se sensíveis mudanças nos níveis tecnológicos dos sistemas de produção, que contribuíram para o aumento da produtividade das principais atividades agrícolas. Ocorreu ainda a expansão do modelo capitalista no campo, mantendo-se, segundo Gasques et al. (2010), inalterada a característica concentradora da apropriação das riquezas geradas. Observou-se a divisão da agricultura em dois segmentos distintos, um subsetor denominado de doméstico e outro de exportador.

Segundo Delgado (2001), as políticas de modernização agrícola brasileira visavam, além do aumento da produção: gerar oferta adequada de alimentos para a população; ofertar matérias-primas para as agroindústrias; gerar receitas por meio do aumento de exportações agrícolas; liberar mão de obra para o setor industrial; e transferir renda para o setor urbano. No estado do Espírito Santo, não foi muito diferente, as metas almejadas foram cumpridas ao mesmo tempo em que desencadeou problemas sociais não planejados, mas previsíveis, como a migração interna e o aumento das desigualdades sociais e regionais. Para melhor entendimento da articulação das políticas públicas e dos seus efeitos nas alterações das atividades agrícolas capixabas, o período em análise foi dividido em quatro décadas.

É consenso que a modernização não foi homogênea na agricultura brasileira. De acordo com Contini et al. (2010), nas regiões menos desenvolvidas, ocorreram entraves ao desenvolvimento tecnológico, ocasionando diferenças na adoção de inovações tecnológicas. Referindo-se aos instrumentos de modernização da agricultura, destacaram-se, entre as políticas agrícolas, o crédito subsidiado, os investimentos em ciência e tecnologia e a extensão rural pública.

As culturas tiveram desempenhos heterogêneos. Para Olivetti e Camargo (1992), foram muitos os motivos responsáveis por essa situação de desequilíbrio. Entre os fatores que influenciaram a composição da produção agrícola podem ser citados, segundo os mesmos autores, o comportamento favorável de preços internacionais de alguns produtos e as alterações nas políticas agrícolas, voltadas para a modernização da agricultura. Acredita-se que pode ser verificada a eficiência dos 
atores no processo de crescimento da produtividade e de evolução da agricultura nas últimas décadas.

Ocorreu um processo intenso de substituição de culturas, que contribuiu fortemente para a alteração da participação dos produtos nas áreas colhidas. As mudanças na composição da produção agrícola podem ser explicadas pelo desequilíbrio da oferta de inovações tecnológicas entre os produtos, ocasionando diferenças nas taxas de produtividades (SOUZA; LIMA, 2002). Agregam-se a isso, ainda, tanto as diferentes condições de preços pagos aos produtores, como a variação dos mesmos.

No estado do Espírito Santo é possível verificar diferentes políticas de fomento agrícola implementadas, influenciando a dinâmica da composição agrícola e provocando alterações na área, na produtividade e na produção de algumas culturas, inclusive, em suas localizações, relacionadas diretamente ao desenvolvimento do setor. O crescimento da produção pode ser em função do efeito área, decorrente das variações na área cultivada; do efeito rendimento, advindo de variações no rendimento das atividades; e do efeito localização geográfica, originado por alterações na localização da produção, associadas ao crescimento da participação de determinada região na oferta do produto, em detrimento de outras.

Nota-se carência de estudos específicos que analisem com profundidade as transformações ocorridas na composição da produção agrícola capixaba. Espera-se que os resultados deste trabalho possam servir de indicadores aos órgãos governamentais, relacionados ao segmento, sobre a necessidade de criação e de ajustes de políticas destinadas ao setor. Além disso, os resultados podem ser úteis a outros pesquisadores na realização de trabalhos científicos relacionados ao tema.

Nesse contexto, objetivou-se analisar e quantificar as alterações ocorridas na composição da produção das principais lavouras exploradas no estado do Espírito Santo, no período de 1970 a 2010. Especificamente, verificou-se a variação da área plantada, a variação da produtividade e a variação locacional, além dos efeitos escala e substituição e do índice de diversificação.

\section{Material e métodos}

O estado do Espírito Santo, localizado na região Sudeste do Brasil, possui uma área de 46.098.571 quilômetros quadrados e encontra-se dividido em 78 municípios (IBGE, [2012?]). Conforme a Figura 1, o estudo considerou as quatro mesorregiões espírito-santenses (Central, Litoral Norte, Noroeste e Sul), formadas por 24, 15, 17 e 22 municípios, respectivamente. 
Figura 1 - Mesorregiões do estado do Espírito Santo com seus respectivos municípios

\section{Noroeste}

Água Doce do Norte
Águia Branca
Alto Rio Novo
Barra de São Francisco
Baixo Guandú
Boa Esperança
Colatina
Ecoporanga
Governador Lindenberg
Mantenópolis
Marilândia
Nova Venécia
Pancas
São Domingos do Norte
São Gabriel da Palha
Vila Pavão
Vila Valério

Sul

Alegre
Apiacá
Atílio Vivácqua
Bom Jesus do Norte
Cachoeiro de Itapemirim
Castelo
Divino de São Lourenço
Dores do Rio Preto
Guaçui
Irupi
Ibatiba
lúna
Ibitirama
Itapemirim
Jerônimo Monteiro
Marataízes
Muqui
Muniz Freire
Mimoso do sul
Presidente Kennedy
São José do Calçado
Vargem Alta

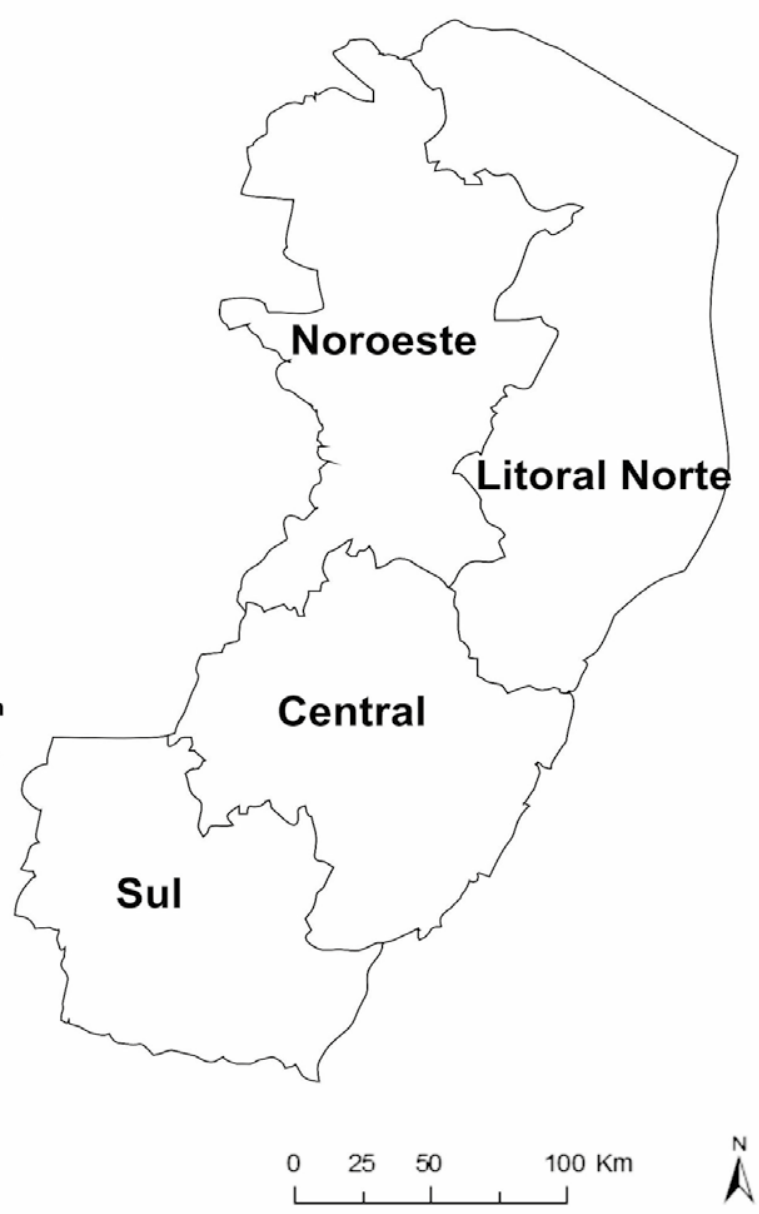

\section{Litoral Norte}

Aracruz

Conceição da Barra

Fundão

Ibiraçu

Jaquaré

João Neiva

Linhares

Montanha

Mucurici

Pinheiros

Ponto Belo

Pedro Canário

Rio Bananal

São Mateus

Sooretama

\section{Central}

Afonso Cláudio

Anchieta

Alfredo Chaves

Brejetuba

Conceição do Castelo

Cariacica

Domingos Martins

Guarapari

Iguaçu

Itarana

Iconha

Laranja da Terra

Marechal Floriano

Piúma

Rio Novo do Sul

Santa Leopodina

Santa Maria de Jetibá

Santa Tereza

São Roque do Canaã

Serra

Venda Nova do Imigrante

Viana

Vila Velha

Vitória

Fonte: adaptado de Baixar Mapas.

Nas análises das alterações na composição da produção agrícola, empregou-se o modelo shift-share na forma proposta por Yokoyama e Igreja (1992). É um método de decomposição estrutural-diferencial, conhecido principalmente por economistas e geógrafos. Entretanto, a utilização mais intensa do método parece ter iniciado após a década de 1960 (ANDRADE, 1980). Segundo Carvalho (1979), o método torna possível a comparação entre os padrões de crescimento dos setores nas diferentes regiões e pode permitir a identificação de fatores que operam em nível nacional daqueles que atuam em nível regional. 
Essa metodologia possibilita investigar as fontes de crescimento da produção, mediante a decomposição desse crescimento em: efeito área, decorrente das variações na área cultivada; efeito rendimento, advindo de variações no rendimento das atividades; e efeito localização geográfica, originado por alterações na localização da produção, associadas ao crescimento da participação de determinada região na oferta do produto em detrimento de outras. Permite ainda que o efeito área possa ser decomposto nos efeitos escala e substituição, a partir dos quais se pode aquilatar em que medida a variação na área ocupada por cada produto deve-se à alteração na área total ou à substituição de uma atividade por outra.

\subsection{Decomposição da variação da produção nos efeitos área, rendimento e localização geográfica}

A análise individual do comportamento da produção de cada produto permite revelar a importância dos efeitos área, rendimento e localização geográfica, cujas expressões matemáticas são derivadas a seguir.

Considerando-se um estudo envolvendo $n$ produtos e $m$ regiões, a produção total do j-ésimo produto (total do sistema), no instante inicial da análise, $t=0$, é dada por:

$$
Q_{j 0}=\sum_{i=1}^{n} A_{i j 0} R_{i j 0}=\sum_{i=1}^{n} \lambda_{i j 0} A_{j 0} R_{i j 0}
$$

em que:

$\mathrm{Q}_{\mathrm{j}}=$ produção total do j-ésimo produto, em que $\mathrm{j}=1,2, \ldots, \mathrm{n}$;

$\mathrm{A}_{\mathrm{ij}}=$ área cultivada do j-ésimo produto, na área da i-ésima região, em que i = 1, 2, m;

$\mathrm{A}_{\mathrm{j}}=$ área total cultivada com o j-ésimo produto;

$R_{\mathrm{ij}}=$ rendimento do j-ésimo produto na i-ésima região;

$\lambda_{\mathrm{ij}}=$ participação do j-ésimo produto na i-ésima região.

De modo semelhante, a produção total do $j$-ésimo produto, no tempo $t=T$, é dada por:

$$
Q_{j T}=\sum_{i=1}^{m} A_{i j T} R_{i j T}=\sum_{i=1}^{m} \lambda_{i j T} A_{j T} R_{i j T}
$$

Supondo que apenas a área total do produto se modificasse entre os instantes $t=0$ e $t=T$, a produção total de $j$, neste último período, seria obtida por: 


$$
Q_{j T}^{A}=\sum_{i=1}^{m} \lambda_{i j 0} A_{j T} R_{i j 0}
$$

Se, além da área total ocupada com o produto $j$, também o rendimento se alterasse em cada região, a produção final seria:

$$
Q_{j T}^{A, R}=\sum_{i=1}^{m} \lambda_{i j 0} A_{j T} R_{i j T}
$$

Finalmente, se a distribuição geográfica da área cultivada $\left(\lambda_{\mathrm{ij}}\right)$ também sofresse modificação, a produção total seria obtida por:

$$
Q_{j T}^{A, R, \lambda}=\sum_{i=1}^{m} \lambda_{i j T} A_{j T} R_{i j T}=Q_{j T}
$$

A mudança total observada na produção do j-ésimo produto, no intervalo de tempo compreendido entre os períodos $t=0$ e $t=T$, é:

$$
Q_{j T}-Q_{j 0}=\sum_{i=1}^{m} \lambda_{i j T} A_{j T} R_{i j T}-\sum_{i=1}^{m} \lambda_{i j 0} A_{j T} R_{i j 0}
$$

ou, de outra forma:

$$
Q_{j T}-Q_{j 0}=\left(Q_{j T}^{A}-Q_{j 0}\right)+\left(Q_{j T}^{A, R}-Q_{j T}^{A}\right)+\left(Q_{j T}-Q_{j T}^{A, R}\right)
$$

em que:

$\mathrm{Q}_{\mathrm{j}}{ }^{-} \mathrm{Q}_{\mathrm{j} 0}=$ variação total na produção

$\mathrm{Q}_{\mathrm{j} \mathrm{T}}^{\mathrm{A}}-\mathrm{Q}_{\mathrm{j} 0}=$ efeito área

$\mathrm{Q}_{\mathrm{j} T}^{\mathrm{A}, \mathrm{T}}-\mathrm{Q}_{\mathrm{jt}}^{\mathrm{A}}=$ Efeito rendimento

$\mathrm{Q}_{\mathrm{jT}}-\mathrm{Q}_{\mathrm{jT}}^{\mathrm{A}, \mathrm{R}}=$ Efeito localização geográfica 
O efeito área pode ser decomposto nos efeitos escala e substituição, a partir dos quais se pode precisar em que medida a variação na área ocupada com cada produto deve-se à alteração na área total ou à substituição de uma atividade por outra. O efeito escala é dado pela variação na área do produto apenas com a alteração do tamanho do sistema, mantendo inalterada sua participação dentro dele. Se os valores forem positivos, representam uma tendência de expansão das culturas; se forem negativos, uma tendência de diminuição na produção das culturas dentro do sistema. Os valores encontrados no efeito escala para cada produto mostram como seria o comportamento de cada cultura, se a ampliação ou a contração da área total fosse distribuída de modo uniforme entre elas. Enquanto o efeito substituição mostra a variação da participação dentro do sistema, referente à diferença entre a variação real da área cultivada, os períodos em análise e o efeito escala (FELIPE, 2008).

Para Yokoyama e Igreja (1992), o efeito substituição negativo não significa, necessariamente, que sua área cultivada tenha sido reduzida; ela pode, simplesmente, ter se expandido, porém, numa magnitude menos proporcional ao crescimento total da área na região em análise. As culturas que apresentam efeito substituição positivo substituíram outras culturas, e as atividades que apresentarem efeito substituição negativo foram substituídas por outras. Por meio do efeito rendimento, obtêm-se as variações da produção decorrentes da produtividade. Por último, o efeito localização geográfica indica as alterações na produção, que ocorrem em função das vantagens locacionais entre as mesorregiões estudadas.

Pela observação das equações 4 e 5, pode-se constatar que o efeito localização geográfica (ELG) é dado por:

$$
E L G=\sum_{i=1}^{m} \lambda_{i j T} A_{j T} R_{i j T}-\sum_{i=1}^{m} \lambda_{i j 0} A_{j T} R_{i j T}=A_{j T}\left(\sum_{i=1}^{m} \lambda_{i j T} R_{i j T}-\sum_{i=1}^{m} \lambda_{i j 0} R_{i j T}\right)
$$

Uma vez que a expressão no interior dos parênteses consiste em uma diferença entre duas médias ponderadas dos rendimentos no tempo $T$ do produto $j$ na região $i\left(\mathrm{R}_{\mathrm{ijT}}\right)$, cujos pesos são as respectivas participações geográficas do produto $\left(\lambda_{\mathrm{ijt}}\right)$, resulta que o efeito localização geográfica é positivo quando se verifica um aumento na participação do produto nas regiões em que ele apresenta o maior rendimento no período $T$.

Com a finalidade de apresentar os resultados dos diversos efeitos explicativos na forma de taxas anuais de crescimento, utiliza-se a metodologia proposta por Igreja (1987). Assim, tomando a expressão 7 e multiplicando-a pela expressão: 


$$
\frac{1}{\left(Q_{j T}-Q_{j 0}\right)}
$$

tem-se:

$$
1=\frac{\left(Q_{j T}^{A}-Q_{j 0}\right)}{\left(Q_{j T}-Q_{j 0}\right)}+\frac{\left(Q_{j T}^{A, R}-Q_{j T}^{A}\right)}{\left(Q_{j T}-Q_{j 0}\right)}+\frac{\left(Q_{j T}-Q_{j T}^{A, R}\right)}{\left(Q_{j T}-Q_{j 0}\right)}
$$

Multiplicando ambos os lados da identidade 9 pela taxa anual média de variação na produção da j-ésima cultura (r), obtém-se:

$$
r=\frac{\left(Q_{j T}^{A}-Q_{j 0}\right)}{\left(Q_{j T}-Q_{j 0}\right)} r+\frac{\left(Q_{j T}^{A, R}-Q_{j T}^{A}\right)}{\left(Q_{j T}-Q_{j 0}\right)} r+\frac{\left(Q_{j T}-Q_{j T}^{A, R}\right)}{\left(Q_{j T}-Q_{j 0}\right)} r
$$

em que $r$ é a taxa anual média de variação na produção do j-ésimo produto, em percentagem ao ano, cuja expressão é a seguinte:

$$
r=\left(\sqrt[T]{\frac{Q_{j T}}{Q_{j 0}}}-1\right) 100
$$

Retomando a equação 10, observa-se que a taxa anual de variação na produção de $j$ é composta dos seguintes efeitos:

$$
\begin{aligned}
& \frac{\left(Q_{j T}^{A}-Q_{j 0}\right)}{\left(Q_{j T}-Q_{j 0}\right)}=\text { Efeito Área(EA), expresso em percentagem de crescimento ao ano } \\
& \frac{\left(Q_{j T}^{A, R}-Q_{j T}^{A}\right)}{\left(Q_{j T}-Q_{j 0}\right)} r=\text { Efeito Rendimento(ER), expresso em percentagem ao ano } \\
& \frac{\left(Q_{j T}-Q_{j T}^{A, R}\right)}{\left(Q_{j T}-Q_{j 0}\right)} r=\text { Efeito Localização Geográfica(ELG), em percentagem ao ano }
\end{aligned}
$$

\subsection{Decomposição do efeito área em efeitos escala e substituição}

A variação da área total ocupada por um produto $j$ qualquer, ocorrida no intervalo de tempo compreendido entre $t=0$ e $t=T$, pode ser representada pela expressão:

$$
A_{j T}-A_{j 0}
$$


a qual, por sua vez, pode ser escrita de outra forma, do que resulta a decomposição do efeito área em dois efeitos:

$$
A_{j T}-A_{j 0}=\left(\gamma A_{j 0}-A_{j 0}\right)+\left(A_{j T}-\gamma A_{j 0}\right)
$$

em que:

$\mathrm{A}_{\mathrm{jT}}-\mathrm{A}_{0}^{\mathrm{j}}=$ Variação da área total ocupada por um produto 1

$\left(\gamma \mathrm{A}_{\mathrm{j} 0}-\mathrm{A}_{\mathrm{j} 0}\right)=$ Efeito escala expresso em hectares

$\left(\mathrm{A}_{\mathrm{jT}}-\gamma \mathrm{A}_{\mathrm{j} 0}\right)=$ Efeito substituição, expresso em hectares

Em 13, $\gamma$ é o coeficiente que mede a modificação na área total cultivada (AT) com todos os produtos considerados na análise (dimensão do sistema) entre os períodos inicial $(\mathrm{t}=0)$ e final $(\mathrm{t}=\mathrm{T})$, sendo ele obtido por:

$$
\gamma=A T_{T} / A T_{0}
$$

O efeito substituição permite observar o comportamento da participação do produto dentro do sistema, apresentando-se negativo quando ocorre a queda na participação do produto considerado e positivo em situação oposta. O primeiro caso implica que o produto em questão foi substituído no sistema por outras atividades, e a segunda situação indica que aquele produto substituiu outras atividades dentro do sistema.

Uma vez que, no sistema de produção, somente se verifica o efeito escala, a soma dos efeitos substituição deve ser nula, ou seja:

$$
\sum_{j=1}^{\mathrm{n}}\left(\mathrm{A}_{\mathrm{jT}}-\gamma A_{j 0}\right)=0
$$

\section{3. Índice de diversificação}

Para sintetizar as mudanças ocorridas no sistema produtivo do estado, foi calculado o Índice de Diversificação $(D)$. No presente contexto, esse índice foi calculado a partir das participações de cada produto $i$ na área total e no valor da produção do sistema do estado, em cada ano $t\left(\mathrm{~S}_{\mathrm{it}}\right)$, mediante a expressão (GASQUES et al., 2010):

$$
D=\frac{1}{\sum S_{i t}^{2}}
$$




\subsection{Variáveis e fonte de dados}

As informações relativas à produção e à área colhida dos produtos, para o estado e as suas mesorregiões, foram extraídas das estatísticas publicadas pela Fundação Instituto Brasileiro de Geografia e Estatística (FIBGE), constantes do Sistema IBGE de Recuperação Automática (Sidra).

A escolha das atividades analisadas baseou-se na importância relativa de cada produto na área total ocupada com culturas permanentes e temporárias, bem como no valor total da produção dessas culturas. Com esse critério, foram selecionas as culturas de café, milho, cana-de-açúcar, feijão, banana, cacau, mandioca, arroz, coco-da-baía, mamão, borracha, laranja, abacaxi, pimenta-do-reino, tomate e maracujá.

Durante o período analisado, a participação média desse conjunto de culturas na área e no valor da produção total das culturas (temporárias e permanentes) superou os $97 \%$, conforme os valores exibidos na Tabela 1.

Tabela 1 - Participação média dos produtos selecionados na área e no valor total da produção vegetal (permanentes e temporárias), referente ao período de 1990 a 2010

\begin{tabular}{l|c|l|c}
\hline \multicolumn{2}{c|}{ Área } & \multicolumn{2}{c}{ Valor da Produção } \\
\hline \multicolumn{1}{c|}{ Classificação } & Participação (\%) & \multicolumn{1}{c}{ Classificação } & Participação (\%) \\
\hline Café & 65,31 & Café & 48,59 \\
Milho & 8,56 & Milho & 8,45 \\
Cana-de-açúcar & 6,81 & Feijão & 6,67 \\
Feijão & 5,58 & Banana & 5,83 \\
Banana & 2,90 & Mamão & 4,90 \\
Cacau & 2,71 & Cana-de-açúcar & 4,42 \\
Mandioca & 2,23 & Mandioca & 4,10 \\
Arroz & 1,59 & Arroz & 3,53 \\
Coco-da-baía & 0,91 & Tomate & 3,39 \\
Mamão & 0,87 & Abacaxi & 2,14 \\
Borracha & 0,65 & Cacau & 2,04 \\
Laranja & 0,30 & Laranja & 1,42 \\
Abacaxi & 0,28 & Borracha & 0,55 \\
Pimenta-do-reino & 0,25 & Pimenta-do-reino & 0,54 \\
Tomate & 0,23 & Coco-da-baía & 0,47 \\
Maracujá & 0,18 & Maracujá & 0,05 \\
\hline Total & 99,35 & Total & 97,09 \\
\hline
\end{tabular}

Fonte: elaborada pelos autores, baseado na Produção Agrícola Municipal do IBGE. 


\section{Resultados e discussão}

\subsection{Período de 1970 a 1980}

Para o período considerado, os resultados apontam crescimento nas áreas de café, tomate, coco, laranja, pimenta-do-reino e mamão, conforme mostra a Tabela 2. Decresceram as áreas de milho, mandioca, arroz, banana, feijão, cacau, cana-de-açúcar e abacaxi.

Os efeitos escala apontam resultados negativos para todas as culturas, o que comprova que os incrementos, observados na área agrícola das culturas analisadas, nas mesorregiões Centro e Noroeste, foram menores do que os decréscimos da área agrícola nas mesorregiões Litoral e Sul. Assim, de maneira geral, houve redução na área agrícola para o agregado das culturas analisadas no Espírito Santo ao longo dos anos 1970.

Tabela 2 - Decomposição da variação da área (ha) com as principais culturas do Estado no período de 1970 a 1980

\begin{tabular}{l|r|r|r|r}
\hline \multirow{2}{*}{ Culturas } & \multirow{2}{*}{ Variação total } & \multicolumn{2}{|c|}{ Efeitos } & \multirow{2}{*}{$\%$} \\
\cline { 3 - 4 } & & Escala & Substituição & \multicolumn{1}{|c}{} \\
\hline Abacaxi & $-270,4$ & $-74,9$ & $-195,5$ & $-0,2$ \\
Arroz & $-18.973,0$ & $-4.363,0$ & $-14.610,0$ & $-16,7$ \\
Banana & $-7.266,0$ & $-2.199,5$ & $-5.066,5$ & $-5,8$ \\
Borracha & 0,0 & 0,0 & 0,0 & 0,0 \\
Cacau & $-4.558,0$ & $-1.735,2$ & $-2.822,8$ & $-3,2$ \\
Café & $67.563,0$ & $-16.272,0$ & $83.835,0$ & 96,0 \\
Cana-de-açúcar & $-1.656,0$ & $-1.778,5$ & 122,5 & 0,1 \\
Coco-da-baía & 443,1 & $-107,6$ & 550,7 & 0,6 \\
Feijão & $-6.481,0$ & $-5.849,8$ & $-631,2$ & $-0,7$ \\
Laranja & 55,0 & $-236,4$ & 291,4 & 0,3 \\
Mamão & 15,0 & $-9,4$ & 24,4 & 0,0 \\
Mandioca & $-35.568,0$ & $-6.324,9$ & $-29.243,1$ & $-33,5$ \\
Maracujá & 0,0 & 0,0 & 0,0 & 0,0 \\
Milho & $-50.555,0$ & $-15.783,2$ & $-34.771,8$ & $-39,8$ \\
Pimenta-do-reino & 53,8 & $-3,5$ & 57,2 & 0,1 \\
Tomate & $2.442,5$ & $-17,2$ & $2.459,7$ & 2,8 \\
\hline
\end{tabular}

* o percentual exibido refere-se à participação da área que cada atividade cede às demais ou toma delas na área total substituída. Fonte: elaborada pelos autores, baseado na Produção Agrícola Municipal do IBGE. 
O maior aumento constatado foi na área de café, de aproximadamente 67,5 mil hectares, e a maior redução foi a no milho, de cerca de 50,5 mil hectares. Em termos absolutos, a cultura que mais absorveu área de outras culturas foi a do café, representando cerca de $96 \%$ do que foi substituído. As culturas que mais foram absorvidas por outras culturas foram a do milho, da mandioca e do arroz. Em termos relativos, os espaços cedidos por essas culturas equivalem, respectivamente, a $39,8 \%, 33,5 \%$ e $16,7 \%$.

As culturas de pimenta-do-reino, tomate, cacau, cana-de-açúcar, coco, feijão, mamão e banana apresentaram ganhos na produção total, e as culturas de laranja, café, abacaxi, arroz, mandioca e milho apresentaram reduções na produção ao longo do período. A exceção do tomate, do café e da laranja, todas as demais atividades apresentaram efeito rendimento positivo, refletindo a melhoria nas técnicas de produção. Constata-se também que o efeito localização geográfica não foi o dominante para a maioria das culturas, exceto para a cultura do mamão.

Observando os efeitos área e rendimento na Tabela 3, é possível destacar que a queda da produção de abacaxi e de mamão deveu-se unicamente à redução da área, visto que o rendimento teve efeito nulo. Para o arroz e o milho, o efeito negativo da área foi o mais relevante, contrabalanceado por um efeito rendimento positivo menor.

Para banana, cacau, feijão e mandioca, o efeito negativo da área foi enormemente compensado pelo sinal positivo do efeito rendimento. Houve efeito área positivo para o café, contudo, o efeito rendimento foi negativo e maior em módulo, fazendo com que a produção total de café decrescesse. A cana-de-açúcar apresentou efeito rendimento positivo e um efeito área relativamente pequeno, o que não comprometeu a produção. $\mathrm{O}$ coco e a pimenta-do-reino apresentaram variação positiva exclusivamente, devido ao aumento da área, uma vez que os demais efeitos foram nulos. A cultura da laranja decresceu, devido tanto à queda na área quanto no rendimento. Por fim, o grande aumento na área de tomate foi contrabalançado por um expressivo decréscimo nos rendimentos.

Em relação ao efeito localização geográfica, as culturas de mamão, arroz e feijão apresentaram efeitos positivos. Isso indica que essas culturas se deslocaram para mesorregiões em que os efeitos rendimento cresceram ao longo da década. Apresentaram efeitos localização geográfica negativos as culturas de mandioca, cana-de-açúcar, banana, tomate e laranja, o que indica que essas culturas migraram para regiões em que o rendimento caiu ao longo da década de 1970. 
Tabela 3 - Decomposição da taxa de crescimento da produção das principais culturas do estado em efeitos área, rendimento e localização geográfica, no período de 1970 a 1980

\begin{tabular}{l|c|c|c|c}
\hline \multirow{2}{*}{\multicolumn{1}{c|}{ Culturas }} & \multicolumn{3}{|c|}{ Efeitos } & \multirow{2}{*}{ Total } \\
\cline { 2 - 4 } & Área & Rendimento & Localização Geográfica & $-3,7$ \\
\hline Abacaxi & $-3,7$ & 0,0 & 0,0 & $-2,4$ \\
Arroz & $-4,2$ & 1,6 & 0,2 & 0,6 \\
Banana & $-2,8$ & 4,1 & $-0,7$ & 0,0 \\
Borracha & - & - & - & 7,4 \\
Cacau & $-1,6$ & 9,0 & 0,0 & $-4,6$ \\
Café & 2,1 & $-6,7$ & $-0,1$ & 5,0 \\
Cana-de-açúcar & $-0,6$ & 9,9 & $-4,2$ & 3,1 \\
Coco-da-baía & 3,1 & 0,0 & 0,0 & 1,7 \\
Feijão & $-0,9$ & 2,5 & 0,1 & $-4,8$ \\
Laranja & $-3,0$ & $-1,4$ & $-0,4$ & 1,3 \\
Mamão & $-5,1$ & 0,0 & 6,4 & $-1,8$ \\
Mandioca & $-5,3$ & 15,2 & $-11,8$ & 0,0 \\
Maracujá & - & - & - & $-1,6$ \\
Milho & $-3,0$ & 1,4 & 0,0 & 8,9 \\
Pimenta-do-reino & 8,9 & 0,0 & 0,0 & 8,1 \\
Tomate & 84,2 & $-75,4$ & $-0,7$ & \\
\hline
\end{tabular}

Fonte: elaborada pelos autores, baseado na Produção Agrícola Municipal do IBGE.

A atividade cafeeira, em 1970, ocupava a maior área colhida de produtos agrícolas. No período compreendido entre 1970 e 1975, observou-se uma redução na área colhida de café e na produtividade média das lavouras de $2 \%$ e $33 \%$, respectivamente. Segundo dados do IBGE, em 1970, a área colhida de café totalizou 190.596 hectares com uma produção de 174.496 toneladas. Em 1975, sofreu uma pequena redução da área colhida, passando para 187.122 hectares com uma produção de 108.484 toneladas. Em 1970, a produtividade média das lavouras foi de aproximadamente 15 sacas de $60 \mathrm{~kg}$ por hectare e, em 1975, reduziu para, aproximadamente, 10 sacas de $60 \mathrm{~kg}$ por hectare. No mesmo ano, a cultura do milho apresentava-se como a segunda maior cultura em área colhida. Nesse ano, contabilizava uma área de 184.981 hectares com uma produção de 162.204 toneladas. Em 1975, a área diminuiu para 150.649 hectares com uma produção de 152.071 toneladas. Em 1980, tanto a área colhida, quanto a produzida, reduziram ainda mais, atingindo 133.988 hectares de área e uma produção de 137.001 toneladas.

A área colhida de cacau, em 1970, era a terceira maior entre as áreas ocupadas por produtos agrícolas no estado. Ocupava uma área de 20.126 hectares com uma produção de 5.889 toneladas de amêndoas. Em 1975, teve sua área alterada para 
21.997 hectares com uma produção 9.472 toneladas. Observa-se que, em 1980, embora a área colhida tenha reduzido para 15.540 hectares em relação ao ano de 1975, a produção de cacau aumentou em relação ao mesmo ano, atingindo 11.985 toneladas.

No ano de 1975, além dessas três atividades agrícolas mencionadas, encontrava-se, entre outras culturas, a de laranja com uma área colhida de 1.595 hectares, respectivamente. De feijão, foram colhidos 68.930 hectares, e de mandioca, 31.840 hectares.

Para Contini et al. (2010), nesta década ainda havia prioridade dos investimentos na indústria e na infraestrutura urbana, que promovia o crescimento do êxodo rural brasileiro. Contudo, Alves e Contini (1999) mencionam que esse processo declinou pelo fato de ter completado o ciclo na maioria das regiões, com exceção das Regiões Norte e Nordeste. Um dos efeitos negativos do processo de modernização foi a expansão da agricultura capitalista: cultivando monoculturas de exportação em detrimento da substituição de áreas, destinadas a produção de alimentos.

\subsection{Período de 1980 a 1990}

Constata-se, na Tabela 4, que, de modo geral, houve um aumento na área de todas as culturas, com exceção da cultura de coco, laranja, mandioca, milho e tomate. Com relação à década anterior, as culturas de abacaxi, arroz, banana, cacau, cana-de-açúcar e feijão reverteram a tendência de queda na área. As culturas de café, mamão e pimenta-do-reino continuaram a tendência de crescimento, ao passo que a de mandioca e milho continuaram com diminuição de área. Por fim, as culturas de coco, laranja e tomate reverteram a tendência de alta verificada na década de 1970.

Todos os efeitos escala mostraram-se positivos, o que indica que houve expansão da área das culturas consideradas ao longo dos anos 1980. As culturas de abacaxi, borracha, café, cana-de-açúcar, feijão, mamão e pimenta-do-reino substituíram áreas das culturas de arroz, banana, cacau, coco, laranja, mandioca, milho e tomate. O café foi responsável por, aproximadamente, $85 \%$ da substituição de outras culturas, a cana-de-açúcar por $9,5 \%$. 
Tabela 4 - Decomposição da variação da área (ha) com as principais culturas do estado no período de 1980 a 1990

\begin{tabular}{|c|c|c|c|c|}
\hline \multirow{2}{*}{ Culturas } & \multirow{2}{*}{ Variação total } & \multicolumn{2}{|c|}{ Efeitos } & \multirow{2}{*}{$\%{ }^{*}$} \\
\hline & & Escala & Substituição & \\
\hline Abacaxi & 726,0 & 302,7 & 423,3 & 0,3 \\
\hline Arroz & $1.780,0$ & $16.013,8$ & $-14.233,8$ & $-9,9$ \\
\hline Banana & $5.995,0$ & $9.236,1$ & $-3.241,1$ & $-2,3$ \\
\hline Borracha & 429,0 & 0,0 & 429,0 & 0,3 \\
\hline Cacau & $5.479,0$ & $7.881,1$ & $-2.402,1$ & $-1,7$ \\
\hline Café & $251.413,0$ & $129.738,6$ & $121.674,4$ & 84,9 \\
\hline Cana-de-açúcar & $23.270,0$ & $9.604,1$ & $13.665,9$ & 9,5 \\
\hline Coco-da-baía & $-416,7$ & 856,3 & $-1.272,9$ & $-0,9$ \\
\hline Feijão & $33.119,0$ & $31.066,3$ & $2.052,7$ & 1,4 \\
\hline Laranja & $-807,0$ & $1.415,8$ & $-2.222,8$ & $-1,6$ \\
\hline Mamão & $3.308,3$ & 62,6 & $3.245,7$ & 2,3 \\
\hline Mandioca & $-18.294,0$ & $19.132,8$ & $-37.426,8$ & $-26,1$ \\
\hline Maracujá & 0,0 & 0,0 & 0,0 & 0,0 \\
\hline Milho & $-12.958,0$ & $67.080,5$ & $-80.038,5$ & $-55,8$ \\
\hline Pimenta-do-reino & $1.909,0$ & 47,6 & $1.861,4$ & 1,3 \\
\hline Tomate & $-1.177,0$ & $1.337,3$ & $-2.514,3$ & $-1,8$ \\
\hline
\end{tabular}

* o percentual exibido refere-se à participação da área que cada atividade cede às demais ou toma delas na área total substituída. Fonte: elaborada pelos autores, baseado na Produção Agrícola Municipal do IBGE.

Nesta década, o crédito rural deixou de ser fomento para o setor agrícola. Em 1983, segundo Lucena (2000), ocorreu aumento dos encargos financeiros do crédito rural e eliminação dos subsídios contidos nas taxas de juros cobradas. As culturas mais substituídas foram as do milho $(55,8 \%)$, da mandioca $(26,1 \%)$ e do arroz $(-9,9 \%)$. Cabe destacar que as principais culturas substituídas são produtos agrícolas destinados ao mercado domésticos, enquanto que as substitutas atendem à cadeia agroexportadora, no caso do café, e à demanda por açúcar e álcool combustível, no caso da cana-de-açúcar.

Por outro lado, Rezende (1999) afirma que o crescimento da agricultura brasileira não pode ser separado das políticas relativas a fertilizantes e máquinas agrícolas. A comercialização de máquinas agrícolas, a partir de 1984, apresentou um 
crescimento nas vendas, mesmo inexistindo crédito subsidiado, que se estendeu até 1987, quando se verificou uma diminuição no ritmo de vendas.

$\mathrm{Na}$ Tabela 5, pode-se observar que, com exceção do cacau e do coco, todas as culturas apresentaram incrementos na produção. Observa-se também que apenas a laranja apresentou efeito localização geográfica negativo, indicando que a produção dessa cultura se deslocou para as mesorregiões em que a produtividade foi menor. Apresentaram efeito localização geográfica positivo as culturas de arroz, banana, café, cana-de-açúcar, feijão, mandioca, milho e tomate, indicando que essas culturas se concentraram em áreas onde a produtividade era maior. As demais culturas não apresentaram efeito localização geográfica.

As culturas de abacaxi, banana, café, coco e pimenta-do-reino tiveram como efeito dominante a área. As culturas de arroz, cacau, cana-de-açúcar, feijão, laranja, mandioca, milho e tomate tiveram como efeito dominante o rendimento. Em nenhuma das culturas o efeito localização geográfica foi dominante, contudo, no caso da cana-de-açúcar, esse efeito foi importante para o aumento da produção. Mesmo com o efeito rendimento negativo, essa cultura apresentou acréscimo na produção, devido à soma dos efeitos área e localização geográfica positivos.

Em 1980, a área colhida de café correspondia a 275.496 hectares com uma produção de 283.789 toneladas. A área colhida de milho, a segunda maior área colhida, totalizava 133.988 hectares com uma produção de 137.001 toneladas. A terceira maior área colhida referia-se à cultura de feijão com uma área de 62.574 hectares e com uma produção de 24.580 toneladas. Entre outras, encontram-se, em ordem decrescente de área colhida, as culturas de arroz, cana-de-açúcar, mandioca, cacau e laranja.

No período compreendido entre 1980 e 1985, observou-se um aumento de, aproximadamente, $60 \%$ na área colhida de café. Já, na produtividade média das lavouras, o aumento situou-se abaixo de 1\%. Segundo dados do IBGE, em 1980, foram colhidos 275.496 hectares cultivados com café, obtendo-se uma produção de 283.759 toneladas. A área colhida do produto elevou-se para 443.040 hectares, em 1985, com uma produção de 478.842 toneladas. Em 1980, a produtividade média das lavouras foi de aproximadamente 17 sacas de $60 \mathrm{~kg}$ por hectare e, em 1985, passou para, aproximadamente, 18 sacas de $60 \mathrm{~kg}$ por hectare. 
Tabela 5 - Decomposição da taxa de crescimento da produção das principais culturas do estado em efeitos área, rendimento e localização geográfica, no período de 1980 a 1990

\begin{tabular}{l|c|c|c|c}
\hline \multirow{2}{*}{ Culturas } & \multicolumn{3}{|c|}{ Efeitos } & \multirow{2}{*}{ Total } \\
\cline { 2 - 4 } & Área & Rendimento & Localização Geográfica & 0,3 \\
Abacaxi & 8,3 & 0,0 & 0,0 & 10,5 \\
Arroz & 0,3 & 9,9 & 0,2 & 2,1 \\
Banana & 3,0 & $-0,9$ & 0,1 & $-6,0$ \\
Cacau & 4,6 & $-10,6$ & 0,0 & 4,7 \\
Café & 7,9 & $-3,9$ & 0,7 & 7,4 \\
Cana-de-açúcar & 8,7 & $-9,2$ & 8,0 & $-2,8$ \\
Coco-da-baía & $-2,8$ & 0,0 & 0,0 & 11,5 \\
Feijão & 3,2 & 5,7 & 2,6 & 0,1 \\
Laranja & $-2,9$ & 3,4 & $-0,5$ & 39,4 \\
Mamão & 39,4 & 0,0 & 0,0 & 4,6 \\
Mandioca & $-3,9$ & 8,4 & 0,1 & 3,2 \\
Milho & $-0,8$ & 3,8 & 0,2 & 35,8 \\
Pimenta-do-reino & 35,8 & 0,0 & 0,0 & 12,9 \\
Tomate & $-2,4$ & 15,3 & 0,1 & \\
\hline
\end{tabular}

Fonte: elaborada pelos autores, baseado na Produção Agrícola Municipal do IBGE.

No contexto brasileiro, a tendência também foi de maior expansão dos produtos destinados à exportação. No período de 1980 a 1989, a produção agrícola expandiu $3,6 \%$ ao ano, o que correspondeu a um crescimento anual per capita de $1,5 \%$. A produção dos produtos domésticos cresceu $2,1 \%$ ao ano, mantendo-se constante a produção per capita. A produção das lavouras de exportação expandiu 4,5\% ao ano ou em torno de $2,5 \%$ per capita ao ano. O rápido crescimento da produção canavieira foi influenciado pelo PROÁLCOOL (MELLO, 1990).

\subsection{Período de 1990 a 2000}

Foi um período em que houve restrição de crédito no Brasil, embora com variações significativas na distribuição entre microrregiões (ASSUNÇÃO; CHEIN, 2007). A Tabela 6 apresenta a variação de área. Com exceção das culturas de arroz, banana, feijão, mandioca, milho e pimenta-do-reino, as demais apresentaram aumento na área colhida no estado do Espírito Santo ao longo da década de 1990. Continuaram com a tendência de crescimento, observado na década anterior, as culturas de abacaxi, borracha, cacau, café, cana-de-açúcar e mamão. As culturas de arroz, banana, feijão e pimenta-do-reino reverteram a tendência de crescimento 
na área, em relação à década de 1980. As culturas de coco, laranja e tomate reverteram a tendência de queda. Por fim, as culturas de mandioca e milho seguiram a tendência de queda, verificada nos anos 1980.

Tabela 6 - Decomposição da variação da área (ha) com as principais culturas do estado no período de 1990 a 2000

\begin{tabular}{|c|c|c|c|c|}
\hline \multirow{2}{*}{ Culturas } & \multirow{2}{*}{ Variação total } & \multicolumn{2}{|c|}{ Efeitos } & \multirow{2}{*}{$\%^{*}$} \\
\hline & & Escala & Substituição & \\
\hline Abacaxi & 651,00 & $-202,20$ & 853,20 & 0,70 \\
\hline Arroz & $-27.268,00$ & $-5.103,10$ & $-22.164,90$ & $-17,80$ \\
\hline Banana & $-3.712,00$ & $-3.702,00$ & $-10,00$ & 0,00 \\
\hline Borracha & $5.357,00$ & $-65,50$ & $5.422,50$ & 4,40 \\
\hline Cacau & 307,00 & $-3.214,40$ & $3.521,40$ & 2,80 \\
\hline Café & $15.586,00$ & $-77.534,10$ & $93.120,10$ & 74,80 \\
\hline Cana-de-açúcar & $1.670,00$ & $-6.451,00$ & $8.121,00$ & 6,50 \\
\hline Coco-da-baía & $7.620,00$ & $-194,70$ & $7.814,70$ & 6,30 \\
\hline Feijão & $-60.615,00$ & $-14.430,00$ & $-46.185,00$ & $-37,10$ \\
\hline Laranja & 628,00 & $-303,90$ & 931,90 & 0,70 \\
\hline Mamão & $2.450,00$ & $-524,10$ & $2.974,10$ & 2,40 \\
\hline Mandioca & $-3.289,00$ & $-2.978,60$ & $-310,40$ & $-0,20$ \\
\hline Maracujá & $1.511,00$ & 0,00 & $1.511,00$ & 1,20 \\
\hline Milho & $-74.063,00$ & $-18.258,90$ & $-55.804,10$ & $-44,80$ \\
\hline Pimenta-do-reino & $-358,00$ & $-305,9$ & $-52,10$ & 0,00 \\
\hline Tomate & 33,00 & $-223,7$ & 256,70 & 0,20 \\
\hline
\end{tabular}

* $O$ percentual exibido refere-se à participação da área que cada atividade cede às demais ou toma delas na área total substituída.

Fonte: elaborada pelos autores, baseado na Produção Agrícola Municipal do IBGE.

Os efeitos escala negativos indicam que houve uma queda generalizada na área total de culturas no estado. Todavia, a maioria das culturas apresentou variação positiva na área. Isso é decorrente da substituição de área entre as culturas ao longo da década. As culturas que mais substituíram outras foram as do café $(74,8 \%)$, da cana de açúcar $(6,5 \%)$ e do coco $(6,3 \%)$. As culturas que mais foram substituídas foram as do milho (44,8\%), do feijão $(37,1 \%)$ e do arroz $(17,8 \%)$. Houve variação negativa na produção de arroz, de banana, de feijão, de mandioca, de milho e de pimenta-do-reino. As demais culturas apresentaram variações positivas. O mecanismo de crédito rural equivalência-produto, criado em 1987, só se tornou uma proposta concreta a partir de 1993 e foi considerado, por Pereira (1996), como um estímulo aos produtores que necessitavam de empréstimos. 
Observa-se, na Tabela 7, que os valores do efeito localização geográfica foram negativos para as culturas de abacaxi, café, cana-de-açúcar e feijão, indicando que essas culturas migraram para regiões onde a produtividade foi menor. Efeitos positivos de localização geográfica foram verificados para as culturas de banana, borracha, coco, laranja, mamão, mandioca e milho, indicando que elas se concentraram em áreas onde a produtividade foi maior. As demais culturas apresentaram efeitos de localização nulos. Cabe destacar que nenhum efeito localização foi dominante, ou seja, nenhum foi o principal na explicação da variação.

Nota-se que o efeito dominante para o crescimento da produção de abacaxi, borracha e laranja foi atribuído à mudança de área, contudo, esse efeito foi amenizado por um efeito rendimento negativo. O efeito negativo da área também foi dominante para a queda na produção de arroz, banana, feijão e milho, contrabalanceado por efeitos rendimento positivos. As culturas de cacau, café, cana-de-açúcar, coco e tomate tiveram como efeito dominante o incremento no rendimento. Dessa forma, esse efeito foi potencializado por efeitos área positivo menos intenso.

Tabela 7 - Decomposição da taxa de crescimento da produção das principais culturas do estado em efeitos área, rendimento e localização, no período de 1990 a 2000

\begin{tabular}{l|c|c|c|c}
\hline \multirow{1}{*}{ Culturas } & & Efeitos & \multirow{2}{*}{ Total } \\
\cline { 2 - 4 } & Área & Rendimento & Localização Geográfica & \\
\hline Abacaxi & 4,3 & $-0,9$ & $-0,6$ & 2,8 \\
Arroz & $-15,6$ & 0,1 & 0,0 & $-15,5$ \\
Banana & $-1,6$ & 0,8 & 0,1 & $-0,7$ \\
Borracha & 32,4 & $-4,5$ & 0,1 & 28,0 \\
Cacau & 0,1 & 5,6 & 0,0 & 5,7 \\
Café & 0,2 & 9,0 & $-0,3$ & 8,9 \\
Cana-de-açúcar & 0,3 & 4,5 & $-0,1$ & 4,7 \\
Coco-da-baía & 7,3 & 32,0 & 3,8 & 43,1 \\
Feijão & $-9,6$ & 1,1 & $-1,0$ & $-9,5$ \\
Laranja & 2,8 & $-0,8$ & 0,8 & 2,8 \\
Mamão & 5,4 & 0,6 & 0,1 & 6,2 \\
Mandioca & $-1,9$ & $-0,5$ & 0,1 & $-2,2$ \\
Maracujá & 0,0 & 0,0 & 0,0 & 0,0 \\
Milho & $-7,7$ & 2,5 & 0,2 & $-5,0$ \\
Pimenta-do-reino & $-2,1$ & $-1,8$ & 0,0 & $-3,9$ \\
Tomate & 0,2 & 2,4 & 0,0 & 2,7 \\
\hline
\end{tabular}

Fonte: elaborada pelos autores, baseado na Produção Agrícola Municipal do IBGE.

O efeito dominante para o crescimento da produção de mamão foi o aumento da área associado a um efeito rendimento também positivo. A redução da produção 
de mandioca e pimenta-do-reino ocorreu mediante efeito negativo e dominante de área associado a um efeito rendimento, também, negativo. Em todo o período, a área colhida de todas as culturas temporárias sofreu redução de $47 \%$ aproximadamente.

\subsection{Período de 2000 a 2010}

Observa-se, na Tabela 8, que as variações positivas na produção de abacaxi, borracha, cana-de-açúcar, coco, mamão e tomate ocorreram mediante efeito área dominante. A variação negativa da produção de arroz, feijão, mandioca e milho foi decorrente do efeito área dominante. Apesar da variação de área positiva para a cultura de maracujá, seu efeito rendimento foi negativo e dominante. O incremento na produção de banana e pimenta-do-reino foi consequência do efeito rendimento dominante. E, finalmente, o decréscimo na produção de cacau, café e laranja foi decorrente de todos os efeitos.

Tabela 8 - Decomposição da variação da área (ha) com as principais culturas do Estado no período de 2000 a 2010

\begin{tabular}{|c|c|c|c|c|}
\hline \multirow{2}{*}{ Culturas } & \multirow{2}{*}{ Variação total } & \multicolumn{2}{|c|}{ Efeitos } & \multirow{2}{*}{$\%^{*}$} \\
\hline & & Escala & Substituição & \\
\hline Abacaxi & 153,0 & $-140,9$ & 293,9 & 0,6 \\
\hline Arroz & $-4.851,0$ & $-438,6$ & $-4.412,4$ & $-8,8$ \\
\hline Banana & $-1.121,0$ & $-1.464,5$ & 343,5 & 0,7 \\
\hline Borracha & $1.740,0$ & $-412,7$ & $2.152,7$ & 4,3 \\
\hline Cacau & $-333,0$ & $-1.523,4$ & $1.190,4$ & 2,4 \\
\hline Café & $-50.129,0$ & $-37.330,7$ & $-12.798,3$ & $-25,7$ \\
\hline Cana-de-açúcar & $37.479,0$ & $-3.132,6$ & $40.611,6$ & 81,4 \\
\hline Coco-da-baía & $1.107,0$ & $-634,5$ & $1.741,5$ & 3,5 \\
\hline Feijão & $-18.901,0$ & $-2.416,8$ & $-16.484,2$ & $-33,1$ \\
\hline Laranja & $-1.064,0$ & $-186,8$ & $-877,2$ & $-1,8$ \\
\hline Mamão & $1.251,0$ & $-419,6$ & $1.670,6$ & 3,3 \\
\hline Mandioca & $-2.322,0$ & $-1.156,8$ & $-1.165,2$ & $-2,3$ \\
\hline Maracujá & 472,0 & $-107,8$ & 579,8 & 1,2 \\
\hline Milho & $-17.382,0$ & $-3.246,0$ & $-14.136,0$ & $-28,3$ \\
\hline Pimenta-do-reino & 677,0 & $-117,3$ & 794,3 & 1,6 \\
\hline Tomate & 388,0 & $-106,9$ & 494,9 & 1,0 \\
\hline
\end{tabular}

* O percentual exibido refere-se à participação na área que cada atividade cede às demais ou toma delas na área total substituída. Fonte: elaborada pelos autores, baseado na Produção Agrícola Municipal do IBGE. 
Tabela 9 - Decomposição da taxa de crescimento da produção das principais culturas nos efeitos área, rendimento e localização geográfica, no período de 2000 a 2010

\begin{tabular}{l|c|c|c|c}
\hline \multirow{2}{*}{\multicolumn{1}{c|}{ Culturas }} & \multicolumn{3}{|c|}{ Efeitos } & \multirow{2}{*}{ Total } \\
\cline { 2 - 4 } Abacaxi & Área & Rendimento & Localização Geográfica & 0,1 \\
Arroz & 0,8 & $-0,7$ & 0,0 & $-15,1$ \\
Banana & $-14,8$ & $-0,2$ & $-0,1$ & 26,9 \\
Borracha & $-0,1$ & 26,8 & 0,2 & 3,6 \\
Cacau & 2,5 & 0,9 & 0,1 & $-6,0$ \\
Café & $-0,2$ & $-5,8$ & 0,0 & $-5,0$ \\
Cana-de-açúcar & $-1,2$ & $-3,9$ & 0,1 & 8,4 \\
Coco-da-baía & 5,8 & 2,1 & 0,5 & 1,2 \\
Feijão & 1,2 & 0,3 & $-0,2$ & $-6,8$ \\
Laranja & $-7,5$ & 0,3 & 0,5 & $-21,0$ \\
Mamão & $-9,4$ & $-11,5$ & 0,0 & 2,1 \\
Mandioca & 1,9 & 0,3 & $-0,1$ & $-0,6$ \\
Maracujá & $-1,5$ & 0,7 & 0,1 & $-12,9$ \\
Milho & 5,4 & $-18,3$ & 0,1 & $-5,2$ \\
Pimenta-do-reino & $-4,8$ & $-0,8$ & 0,3 & 8,5 \\
Tomate & 2,8 & 5,8 & 0,0 & 3,0 \\
\hline
\end{tabular}

Fonte: elaborada pelos autores, baseado na Produção Agrícola Municipal do IBGE.

Entre os anos de 2000 e 2010, verificou-se que as áreas cultivadas com culturas temporárias mantiveram-se sem expressivas variações. Observou-se que a maior área plantada correspondeu à do ano de 2004, e a menor, à do final do período, em 2010. No período, a área colhida com todas as culturas temporárias sofreu uma redução de $4 \%$ aproximadamente. Considerando apenas as últimas três décadas, verifica-se queda de $21,25 \%$ na área colhida total com todas as culturas temporárias e permanentes. Para Souza et. al. (2013), o crédito via Pronaf, na última década, expandiu, a princípio, com o aumento do número de contratos e, a partir de 2003, com o aumento no tamanho médio dos contratos e com a crescente participação de regiões de agricultura mais capitalizada, via aquisição de máquinas e equipamentos.

No que se refere às quatro mesorregiões, os dados indicam que, em todas elas, houve uma redução no número de culturas responsáveis pela formação da área total plantada no estado. Observa-se ainda que essa redução foi gradual nas cinco décadas que compõem o período estudado. As mesorregiões Noroeste, Centro e Sul foram as que apresentaram maiores reduções do número de lavouras na 
composição da área média total do estado. Em todo o estado, a redução do número de culturas responsáveis pela média da área plantada reduziu mais de 58,14\%, comparando 2010 com 1970. Assim, o sistema produtivo do estado está cada vez mais concentrado em poucos produtos, já que muitos produtos cultivados no passado perderam sua importância.

Os cálculos dos índices para as áreas das culturas mostram que o índice de diversificação, em 1970, apresentaram magnitudes maiores (em torno de 4,0), em comparação com os mesmos índices em 2010 (em torno de 2,0), conforme Tabela 10.

Tabela 10 - Índices de diversificação das áreas médias plantadas com as principais culturas no estado do Espírito Santo e nas suas mesorregiões, no período de 1970 a 2010

\begin{tabular}{l|l|l|l|l|l}
\hline LOCAL & 1970 & 1980 & 1990 & 2000 & 2010 \\
\hline Espírito Santo & 4,85 & 3,67 & 2,68 & 1,96 & 2,03 \\
Mesorregião Noroeste & 3,46 & 2,75 & 2,22 & 1,32 & 1,31 \\
Mesorregião Litoral & 4,09 & 3,75 & 3,61 & 3,02 & 3,18 \\
Mesorregião Centro & 4,45 & 4,31 & 2,85 & 2,26 & 1,95 \\
Mesorregião Sul & 4,18 & 3,81 & 2,12 & 1,74 & 1,56 \\
\hline
\end{tabular}

Fonte: elaborada pelos autores, baseado na Produção Agrícola Municipal do IBGE.

A tabela indica que o sistema produtivo do estado está, cada vez mais, concentrado em poucos produtos, já que muitos produtos cultivados no passado perderam sua importância relativa em 2010. Na mesorregião Noroeste, a diversificação caiu de 3,46, em 1970, para 1,31. Na mesorregião Litoral, o índice teve uma menor variação, no mesmo período, saindo de 4,09 para 3,18. Na mesorregião Centro, o índice variou de 4,45 para 1,95. Na mesorregião sul, o índice variou de 4,18, em 1970, para 1,56, em 2010.

Tabela 11 - Índice de diversificação do valor médio da produção agrícola no estado do Espírito Santo e em suas mesorregiões, no período de 1990 a 2010

\begin{tabular}{l|l|l|l}
\hline \multicolumn{1}{c|}{ LOCAL } & 1990 & 2000 & 2010 \\
\hline Espírito Santo & 2,68 & 1,87 & 2,57 \\
Mesorregião Noroeste & 2,95 & 1,30 & 1,27 \\
Mesorregião Litoral & 5,27 & 2,71 & 3,56 \\
Mesorregião Centro & 4,53 & 2,14 & 2,20 \\
Mesorregião Sul & 2,24 & 1,40 & 1,76 \\
\hline
\end{tabular}

Fonte: elaborada pelos autores, baseado na Produção Agrícola Municipal do IBGE. 
Os índices de diversificação no valor médio da produção foram calculados no período entre os anos de 1990 e 2010, em função de não se encontrar valores para as duas décadas anteriores. Observa-se, na Tabela 11, que as mesorregiões Noroeste e Sul foram as que mais concentraram sua produção em um número reduzido de produtos. A primeira saiu de um índice de 2,95 para 1,27, e a segunda, de 2,24 para 1,76. As que menos concentraram sua produção foram as mesorregiões Litoral e Centro: a primeira saiu de um índice de 5,57 para 3,56, e a segunda, de 4,53 para 3.56. Considerando todo o estado, o índice apresentou pequena variação no período, em 1990 era de 2,68 e passou para 2,57 em 2010.

\section{Conclusões}

Os resultados confirmam alterações na composição da produção agrícola durante o período de 1970 a 2010. Constata-se que houve alterações significativas nas áreas colhidas, na localização geográfica, no rendimento das culturas e nos índices de diversificação de área e de valor de produção das quatro mesorregiões do estado do Espírito Santo.

As mudanças de área, de produção e de produtividade ocorreram em todas quatro décadas analisadas. A cultura do café apresentou a maior expansão em área e efeitos positivos, tanto em escala, quanto em substituição. A taxa de crescimento da produção cafeeira foi positiva nos efeitos área e rendimento. As culturas de milho, arroz e feijão foram as que mais decresceram em área e tiveram efeitos negativos, tanto em escala, quanto em substituição. Essas culturas apresentaram taxas de crescimento da produção negativas e redução de efeitos área e rendimento.

O índice de diversificação da área revelou que houve uma concentração de área. A magnitude desse índice reduziu pela metade no período entre 1970 e 2010. Assim, constatou que o sistema produtivo do estado está cada vez mais concentrado em poucos produtos. Esse índice, para o valor de produção, também indicou maior concentração da produção a todas as mesorregiões. As culturas que mais foram absorvidas por outras foram as de arroz, milho, feijão e laranja, enquanto a cultura de café foi a que mais absorveu área de outras culturas.

As políticas agrícolas e econômicas afetaram a dinâmica da localização e da diversificação da produção agrícola das mesorregiões. Recomenda-se estudos mais específicos que avaliem o cenário antes da criação de políticas e da geração de inovações, para identificar as contribuições das políticas de fomento nos impactos de mudanças de área, de produção, de rendimento e de localização geográfica. 


\title{
Dinámica de la producción y la diversificación de cultivos del Espírito Santo de 1970 a 2010
}

\author{
Resumen
}

El objetivo del estudio fue analizar la dinámica de los principales cultivos en el estado de Espíritu Santo, de 1970 a 2010. Se utilizó el método de cambio de acciones de cuantificar el área de variación, el ingreso, la ubicación geográfica y niveles de diversificación del valor de área y producción. Se encontró que hubo cambios área, la producción y la productividad. En las cuatro décadas analizadas, la cultura del café aumentó la mayoría de la zona (148\%) y los efectos positivos tanto en escala en su lugar. Mientras que los cultivos de maíz, arroz y frijoles fueron los más disminuyeron en el área y con efectos negativos tanto en escala en su lugar. Sus tasas de producción fueron negativos con efectos de reducción de área y los ingresos. El índice de diversidad reveló que no había zona de concentración y en unos pocos productos.

Palabras clave: Agricultura capixaba. Diversificación. Efecto área y de rendimiento. Método shift-share.

\section{Dynamics in the production and diversification of the crops cultivated in the Espírito Santo from 1970 to 2010}

\begin{abstract}
The study aimed to analyze the dynamics of the main crops in the state of Espírito Santo, from 1970 to 2010 . We used the shift-share method to quantify variation area, income, geographical location and levels of diversification of the area and production value. It was found that there were changes area, production and productivity. In the four decades analyzed, the coffee culture increased the most in area (148\%) and positive effects both scale instead. While the crops of maize, rice and beans were the most decreased in area and with negative effects both scale instead. Their production rates were negative with area reduction effects and income. The diversity index revealed that there were concentration area and in a few products.
\end{abstract}

Keywords: Agriculture of Espírito Santo. Diversification. Area effect and yield. Shift-share method. 


\section{Referências}

ALVES, E. L. M.; CONTINI, E. O empobrecimento da agricultura brasileira. Revista de Política Agrícola, Brasília, v. 8, n. 3, p. 5-9, ago. 1999.

ANDRADE, T. A. Aplicação do método estrutural-diferencial: comentário. Revista Brasileira de Economia, Rio de Janeiro, v. 34, n. 4, p. 439-444, jul./set. 1980.

ASSUNÇÃO, J.; CHEIN, F. Condições de crédito no Brasil rural. Revista de Economia e Sociologia Rural, Rio de Janeiro, v. 45, n. 2, p. 367-407, abr./jun. 2007.

BAIXAR MAPAS. Mesorregiões do Espírito Santo. 2012. 1 mapa, color. Escala: 1: 2500 000. Disponível em: <http://www.baixarmapas.com.br/mapa-do-espirito-santo-mesorregioes/>. Acesso em: 08 abr. 2017.

CARVALHO, L. W. R. de. Uma aplicação do método estrutural-diferencial para a análise do desenvolvimento do Centro-Oeste. Revista Brasileira de Economia, Rio de Janeiro, v. 33, n. 3, p. $413-440$, jul./set. 1979 .

CONTINI, E. et al. Dinamismo da agricultura brasileira. Revista de Política Agrícola, Brasília, v. 1 , n. 1, p. 43-63, jul./set. 2010.

DELGADO, G. da C. Expansão e modernização do setor agropecuário no pós-guerra: um estudo da reflexão agrária. Revista Estudos Avançados, São Paulo, v. 15, n. 43, p. 157-172, set./dez. 2001.

FELIPE, F. I. Dinâmica da Agricultura no Estado de São Paulo entre 1990 e 2005: uma análise através do modelo Shift Share. Revista de Economia Agrícola, São Paulo, v. 55, n. 2, p. 61-73, jul./dez. 2008.

GASQUES, J. G. et al. Produtividade total dos fatores e transformações da agricultura brasileira: análise dos dados dos censos agropecuários. In: CONGRESSO DA SOCIEDADE BRASILEIRA DE ECONOMIA, ADMINISTRAÇÃO E SOCIOLOGIA RURAL, 48., 2010, Campo Grande. Anais... Brasília: SOBER, 2010. p. 1-21.

INSITUTO BRASILEIRO DE GEOGRAFIA E ESTATÍSTICA (IBGE). Sistema IBGE de Recuperação Automática - SIDRA. Produção Agrícola Municipal - PAM, anos de 1970-2010. [2012?]. Disponível em: <https://sidra.ibge.gov.br/pesquisa/pam/tabelas>. Acesso em: 27 nov. 2012.

LUCENA, R. B. O Papel da agricultura no desenvolvimento econômico brasileiro, 1980/1998. 2000. 154 f. Tese (Mestrado em Economia) - Curso de Pós-Graduação em Economia da Universidade Federal do Rio Grande do Sul, Porto Alegre, 2000.

MELLO, F. B. H. O crescimento agrícola brasileiro dos anos 80 e as perspectivas para os anos 90 . Revista de Economia Política, São Paulo, v. 10, n. 3, p. 39-45, 1990.

OLIVETTI, M. P. A.; CAMARGO, A. M. M. P. Evolução da composição agrícola no Brasil e principais regiões produtoras. Revista Agricultura em São Paulo, São Paulo, v. 39, n. 1, p. 155-177, 1992.

PEREIRA, J. C. Crédito rural e o desenvolvimento da agricultura brasileira. 1996. 76 f. Monografia (Graduação em Ciências Econômicas) - Universidade Federal do Rio Grande do Sul, Porto Alegre, 1996. 
REZENDE, G. de C. Conjuntura macroeconômica e política agrícola no período 1992/97: dos velhos aos novos instrumentos. Revista de Política Agrícola, Brasília, v. 8, n. 3, p. 25-35, 1999.

SOUZA, P. M.; LIMA, J. E. Mudanças na composição da produção agrícola no Brasil 1975-95. Revista Econômica do Nordeste, Fortaleza, v. 33, n. 3, p. 632-659, 2002.

SOUZA, P. M. et al. Análise da evolução do valor dos financiamentos do Pronaf-crédito (1999 a 2010): número, valor médio e localização geográfica dos contratos. Revista Economia e Sociologia Rural, Brasília, v. 51, n. 2, abr./jun. 2013.

YOKOYAMA, L. P.; IGREJA, A. C. M. Principais lavouras da região Centro-Oeste: variações no período 1975-1987. Pesquisa Agropecuária Brasileira, Brasília, v. 27, n. 5, p. 727-736, maio 1992. 